\title{
Functional Plasticity of Regenerated and Intact Taste Receptors in Adult Rats Unmasked by Dietary Sodium Restriction
}

\author{
David L. Hill and Lynnette M. Phillips \\ Department of Psychology, University of Virginia, Charlottesville, Virginia 22903-2477
}

\begin{abstract}
Unilateral chorda tympani nerve sectioning was combined with institution of a sodium-restricted diet in adult rats to determine the role that environment has on the functional properties of regenerating taste receptor cells. Rats receiving chorda tympani sectioning but no dietary manipulation (cut controls) and rats receiving only the dietary manipulation (diet controls) had normal responses to a concentration series of $\mathrm{NaCl}$, sodium acetate ( $\mathrm{NaAc}$ ), and $\mathrm{NH}_{4} \mathrm{Cl}$. However, responses from the regenerated nerve in $\mathrm{NaCl}-$ restricted rats (40-120 d postsectioning) to $\mathrm{NaCl}$ and $\mathrm{NaAc}$ were reduced by as much as $30 \%$ compared to controls, indicating that regenerating taste receptors are influenced by environmental (dietary) factors. Responses to $\mathrm{NH}_{4} \mathrm{Cl}$ were normal; therefore, the effect appears specific to sodium salts. Surprisingly, in the same rats, $\mathrm{NaCl}$ responses from the contralateral, intact chorda tympani were up to $40 \%$ greater than controls. Thus, in the same rat, there was over a twofold difference in sodium responses between the right and left chorda tympani nerves. A study of the time course of the functional alterations in the intact nerve revealed that responses to $\mathrm{NaCl}$ were extremely low immediately following sectioning (about $20 \%$ of the normal response), and then increased monotonically during the following $\mathbf{5 0} \mathrm{d}$ until relative response magnitudes became supersensitive. This function occurred even when the cut chorda tympani was prevented from reinnervating lingual epithelia, demonstrating that events related to regeneration do not play a role in the functional properties of the contralateral side of the tongue. The anomalies in responses in the regenerated and the uncut nerves are attributable to functional alterations in the sodium transducer, the amiloride-sensitive sodium channel. Specifically, sodium transduction via the channel is decreased or increased from normal levels, depending on the experimental conditions. Although efferent neural effects cannot be disregarded, the present results suggest that alterations in circulating factors may modulate response properties of intact, lingual taste receptor cells.
\end{abstract}

[Key words: regeneration, taste, sodium, chorda tympani nerve, supersensitivity, rat, tongue, receptor interactions, amiloride, gustation, receptor cells, transduction]

\footnotetext{
Received June 28, 1993; revised Oct. 1, 1993; accepted Oct. 26, 1993.

We thank Mr. Robert Stewart for comments on earlier versions of the manuscript. This work was supported by NIH Grant DC00407.

Correspondence should be addressed to Dr. David L. Hill, Department of Psychology, Gilmer Hall, University of Virginia, Charlottesville, VA 22903-2477.

Copyright (C) 1994 Society for Neuroscience 0270-6474/94/142904-07\$05.00/0
}

Taste receptor cells located on the anterior third of the tongue are innervated by the chorda tympani nerve, a branch of the facial nerve. While the fundamental function of the chorda tympani is to transmit gustatory information from fungiform papillae to the CNS, another crucial function of the nerve is to maintain the morphological and physiological integrity of taste receptors. In mammals, sectioning the chorda tympani nerve results in significant degeneration of taste buds unilateral to the cut with a corresponding loss of gustatory function. Importantly, taste buds reappear in fungiform papillae and functional responses are restored following regeneration of the cut nerve (Olmsted, 1921; Guth, 1971; Cheal and Oakley, 1977; Cheal et al., 1977; Hård af Segerstad et al., 1989). These phenomena have been used as a model system to study trophic maintenance of target cells by afferent neuronal elements (e.g., Oakley et al., 1984). Although the morphological aspects of the loss and subsequent reappearance of taste buds following denervation and regeneration of the nerve are relatively well characterized, the rules involved in establishing the response properties of regenerating taste receptor cells are not understood.

Since parallels exist between the formation of taste buds during early development and the reformation of taste buds in adults after nerve section (Zelena, 1964; Farbman, 1965; Oakley and Benjamin, 1966; Mistretta, 1972), a determination of important variables in restoration of taste function might be accomplished by using experimental approaches employed in developmental studies. Previous work from our laboratory has indicated that environmental influences during development play a critical role in determining taste function (Hill, 1987; Hill and Przekop, 1988). Specifically, early dietary sodium restriction continued throughout pre- and postnatal development in rat results in a failure of functional amiloride-sensitive sodium channels, the transducer for sodium taste (Garty and Benos, 1988), to develop on the tongue. This occurs even though responses to nonsodium salts and nonsalt stimuli develop normally. Therefore, environmental manipulations can have selective and profound influences on developing salt taste. We hypothesize that environmental influences have similar effects on the function of the regenerating taste system in adults.

In addition to studying the regenerated chorda tympani, we were also interested in the physiological effects that occur on the unoperated side of the tongue following denervation of contralateral taste receptors. Evidence suggests that functional effects distant to denervated receptor populations may also occur. For example, Bartoshuk et al. (1992) show that human taste function on one side of the tongue can be altered following anesthetization of taste nerves on the contralateral side. They concluded that such effects occur via central pathways. In con- 
trast, Simon et al. (1993) suggest, based upon data from in vitro studies on rat and dog lingual epithelia, that circulating factors may play a role in interactions between the two sides of the tongue. The emerging idea that interactions occur between the two sides of the tongue is an important one because it raises the possibility that taste function can be regulated by local, circulating factors.

\section{Materials and Methods}

Animals, surgical nerve cut preparation, and dietary manipulations. Male and female Sprague-Dawley rats purchased from Hilltop Laboratories (Scottdale, PA) were 40-60 d old at the time of the initial nerve section and/or dietary manipulation. Rats receiving nerve section were initially injected with $0.1 \mathrm{ml}$ of atropine sulfate $(0.54 \mathrm{mg} / \mathrm{ml}$, i.p.) and subsequently anesthetized with sodium Brevital $(60 \mathrm{mg} / \mathrm{kg}$, i.p.). The left chorda tympani nerve was exposed in the neck and sectioned between the anterior belly of the digastric and the masseter muscles where the chorda tympani nerve bifurcates from the lingual branch of the trigeminal nerve. Thus, the lingual branch of the trigeminal nerve remained intact. Rats receiving nerve sections were then either (1) injected with furosemide (two injections of $10 \mathrm{mg}$ each within $24 \mathrm{hr}$ ) and placed on a sodium deficient diet $(0.03 \% \mathrm{NaCl}$; ICN Biochemicals) throughout the experiment or (2) continued on standard laboratory chow $(1.0 \%$ $\mathrm{NaCl}$ ) and distilled water. An additional group of rats was injected with furosemide and placed on the sodium-deficient diet but received no nerve section. Therefore, this study reports findings from three groups: (1) unilateral chorda tympani nerve section followed by a low-sodium diet, (2) unilateral chorda tympani nerve section with a sodium-replete diet (cut controls), and (3) intact chorda tympani nerve with a lowsodium diet (diet controls).

Neurophysiology. Recordings from the left and/or right chorda tympani nerve were accomplished in rats between 4 and $82 \mathrm{~d}$ following surgical and dietary manipulations. Rats were anesthetized with an intraperitoneal injection of urethane $(1.2 \mathrm{~g} / \mathrm{kg}$ body weight); supplementary injections were given as needed to maintain a surgical level of anesthesia. After a surgical level of anesthesia was achieved, the hypoglossal nerve was cut bilaterally to prevent tongue movements. Animals were then tracheotomized and placed in a nontraumatic headholder (Erickson, 1966). Body temperature was regulated between $36^{\circ} \mathrm{C}$ and $39^{\circ} \mathrm{C}$ by keeping rats on a water-circulating heating pad. By use of a lateral dissection of the head, the left and/or right chorda tympani nerve was exposed, cut near its entrance into the tympanic bulla, and dissected from underlying tissues. The nerve was desheathed and placed on a platinum electrode with an indifferent electrode in nearby tissues. Multifiber neural activity from the whole nerve was amplified, displayed on an oscilloscope, and monitored with an audio amplifier. For data analysis, the amplified signal was passed through an integrator with a time constant of $1.0 \mathrm{sec}$ or $2.0 \mathrm{sec}$ (Beidler, 1953; Harper and Knight, 1987), and the summated electrical activity was displayed on a rectilinear pen recorder. This measure of the neural response reflects the sum of single-fiber responses (Beidler et al., 1955; Hill et al., 1982) and is an appropriate measure for studying responses from a large population of taste receptors.

Stimuli and stimulation procedures. Responses were recorded during stimulation of the anterior tongue with a concentration series $(0.05-0.5$ M) of $\mathrm{NaCl}, \mathrm{NH}_{4} \mathrm{Cl}$, and sodium acetate $(\mathrm{NaAc})$. All chemicals were dissolved in distilled water and kept at room temperature during experiments. Fifteen milliliters of each stimulus were applied to the anterior tongue via a syringe followed about $20 \mathrm{sec}$ later by a $1 \mathrm{~min}$ distilled water rinse. The stability of each preparation was monitored by application of $0.5 \mathrm{M} \mathrm{NH}_{4} \mathrm{Cl}$ before and after each concentration series. A recording was considered to be stable when the $0.5 \mathrm{M} \mathrm{NH}_{4} \mathrm{Cl}$ response magnitudes at the beginning and end of a stimulation series deviated $<10 \%$. Only data from stable recordings were used in the data analysis. Responses were also recorded to a concentration series of $\mathrm{NaCl}$, along with the $0.5 \mathrm{M} \mathrm{NH} \mathrm{NH}_{4} \mathrm{Cl}$ reference stimulus, after lingual application of the epithelial sodium transport blocker amiloride hydrochloride. After a 5 min lingual application of $500 \mu \mathrm{M}$ amiloride, the same stimulation procedure was used as described before except the rinse and solvent for all stimuli consisted of $100 \mu \mathrm{M}$ amiloride. Typically, each concentration series was done once for each animal.

Response magnitudes were measured as the height of the summated response $20 \mathrm{sec}$ after stimulus application. Therefore, only the steady
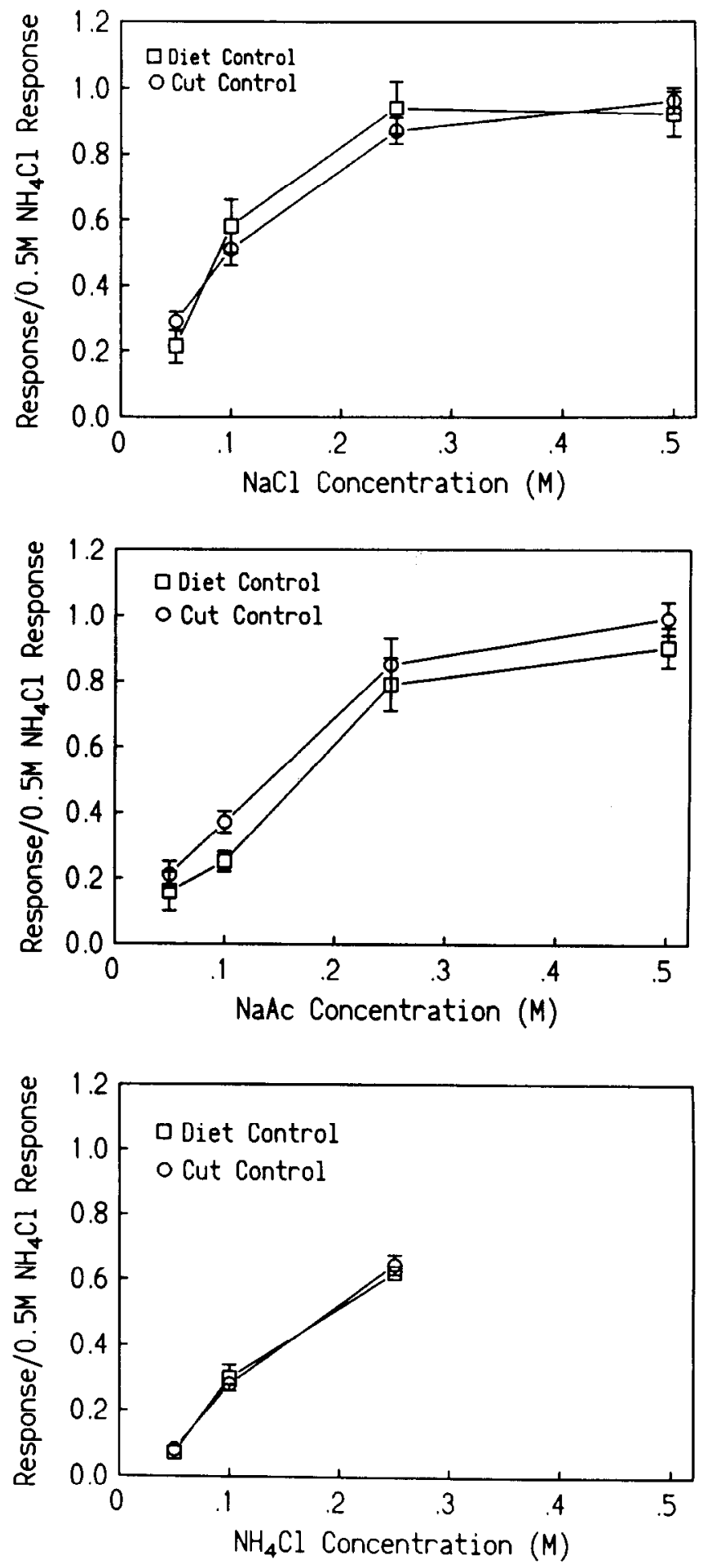

Figure 1. Mean ( \pm SEM) relative responses from the chorda tympani nerve in diet and cut controls to a concentration series of $\mathrm{NaCl}$ (top), $\mathrm{NaAc}$ (middle), and $\mathrm{NH}_{4} \mathrm{Cl}$ (bottom). Responses to all stimuli were similar between diet and cut controls and are similar to responses from the chorda tympani in normal adult rats.

state portion of the response was measured. Because it is not valid to compare absolute response magnitudes between animals or groups (Beidler, 1953), ratios for all responses were calculated relative to the 0.5 M NH $\mathrm{NH}_{1} \mathrm{Cl}$ response. The $0.5 \mathrm{M} \mathrm{NH}_{4} \mathrm{Cl}$ stimulus was chosen as the standard because responses to it are unaffected by lingual application of amiloride, and $0.5 \mathrm{M} \mathrm{NH}_{4} \mathrm{Cl}$ elicits large, unchanging responses under conditions of sodium deprivation and during development (Hill et al., 1982; Hill and Bour, 1985; Hill, 1987). 


\section{CUT CT}

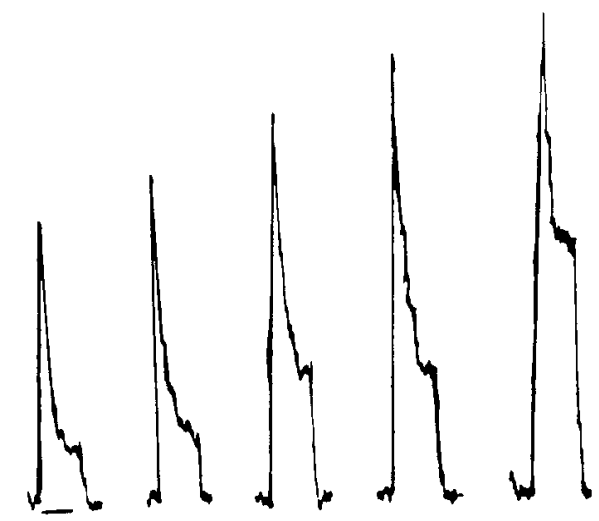

DIET CONTROL

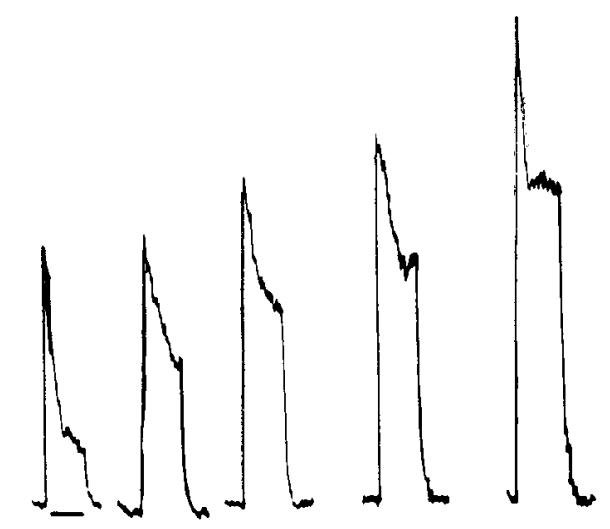

Figure 2. Integrated responses to a concentration series of $\mathrm{NaCl}$ and $0.5 \mathrm{M}$ $\mathrm{NH}_{4} \mathrm{Cl}$ from the chorda tympani nerve that regenerated while the rat was fed a sodium-deficient diet (top; Cut CT), the chorda tympani nerve in a diet control (middle; Diet Control), and the chorda tympani ncrve that was contralateral to the nerve shown at the top, but was not sectioned (bottom; Uncut $C T$ ). Steady state responses to $\mathrm{NaCl}$ compared to those to $\mathrm{NH}_{4} \mathrm{Cl}$ were lower in the regenerated nerve and higher in the intact nerve compared to controls. For presentation purposes, each of the three records were photographically reduced or enlarged accordingly to match the other two records visually. Time calibration (lines under the $0.05 \mathrm{M} \mathrm{NaCl}$ responses), $20 \mathrm{sec}$.

UNCUT CT

Data analyses. Planned, a priori comparisons were used to examine differences between mean responses of the two control groups (cut control and diet control). Responses from the two control groups were pooled (see below) and were compared with responses from the regenerated chorda tympani nerve and uncut, contralateral chorda tympani nerve. Accordingly, the $\alpha$-level of 0.05 was divided by the number of comparisons at each concentration (0.05/4 comparisons).

\section{Results}

Responses from control groups

Responses to a concentration series of $\mathrm{NaCl}, \mathrm{NaAc}$, and $\mathrm{NH}_{4} \mathrm{Cl}$ were similar between diet control $(n=7)$ and cut control $(n=$
$8)$ rats $(t=0.46-1.25 ; p=0.23-0.66$; Fig. 1$)$. Therefore, data were pooled into one control group and are referred to below as "controls."

\section{Responses from the regenerated chorda tympani nerve}

Following regeneration of the sectioned chorda tympani nerve, taste receptor cells reappear and become functional (Cheal and Oakley, 1977). Recordings of taste responses from the regenerated chorda tympani nerve were attempted in both sodiumrestricted and control rats beginning $35 \mathrm{~d}$ postsectioning. In both groups, robust taste responses were first obtained approximately 

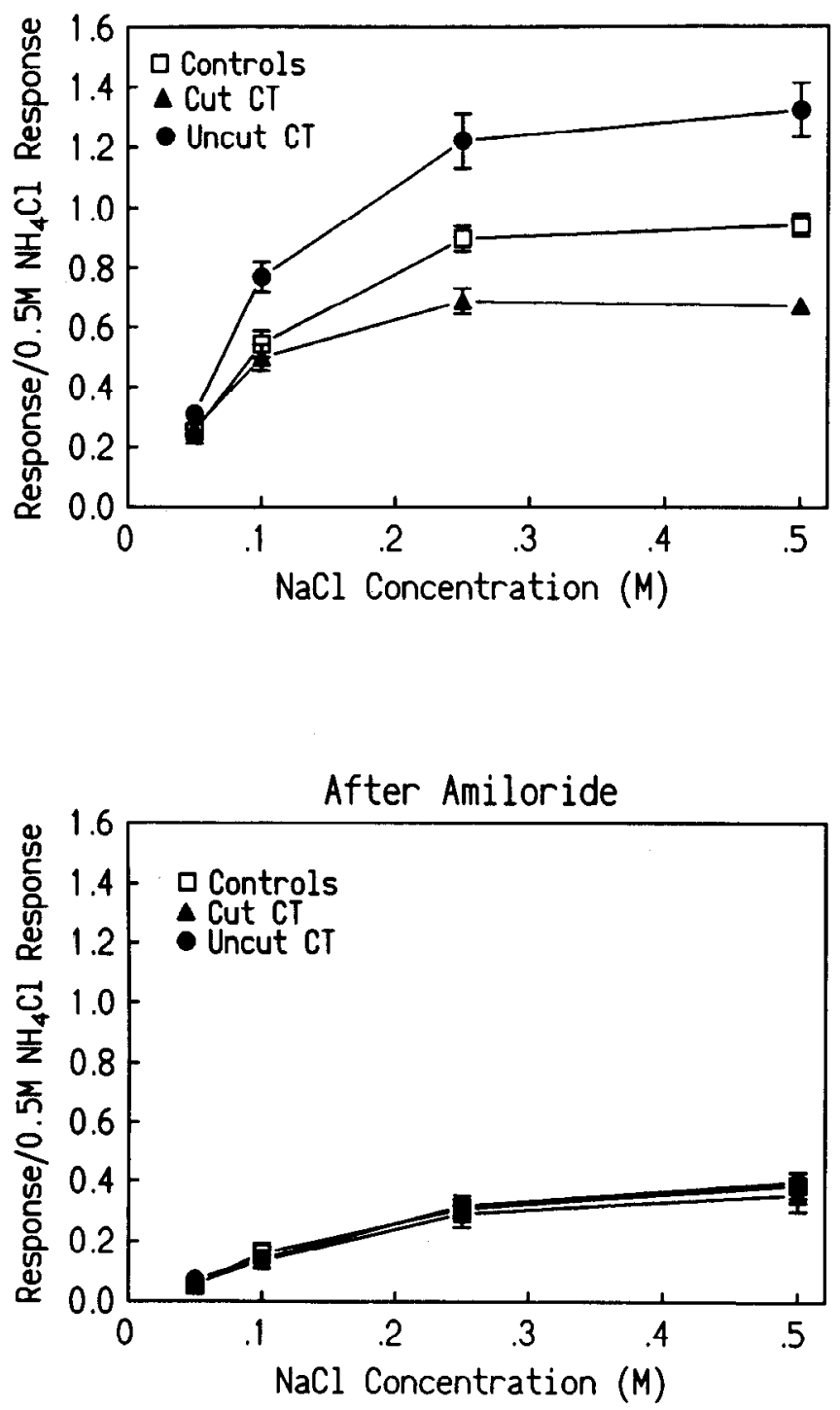

Figure 3. Mean ( \pm SEM) relative responses to a concentration series of $\mathrm{NaCl}$ in the regenerated chorda tympani nerve in controls, sodiumrestricted rats ( $C u t C T$ ), and the intact nerve in rats where the contralateral chorda tympani regenerated under sodium restriction (Uncut $C T$ ). Responses are shown before (top) and after (bottom) lingual application of the sodium transport blocker amiloride.

$45 \mathrm{~d}$ following sectioning. That is, dietary conditions did not influence the time when responses could first be obtained. The time period from nerve section to recording taste responses is longer than the period observed in gerbil (Cheal and Oakley, 1977), but shorter than that noted in dog (Simon et al., 1993). It is unclear whether species and/or methodological differences account for the apparent extended period that we observed. Although this similarity was seen between sodium-restricted and controls, persistent differences between groups existed in the magnitude of responses to sodium stimuli. Responses to $0.25 \mathrm{M}$ and $0.5 \mathrm{M} \mathrm{NaCl}$ and $\mathrm{NaAc}$ from the regenerated nerve in sodium-restricted rats $(n=8)$ were $20-30 \%$ lower than in controls $(t=2.15-5.23 ; p=0.04-0.0001$; Figs. 2-4). By comparison, responses to the lower concentrations of the sodium salts $(0.05 \mathrm{M}$ and $0.1 \mathrm{M})$ and to all concentrations of $\mathrm{NH}_{4} \mathrm{Cl}(p$ $>0.10$ ) were similar between groups (Fig. 4). Responses from the regenerated nerve in sodium-restricted rats remained sig-
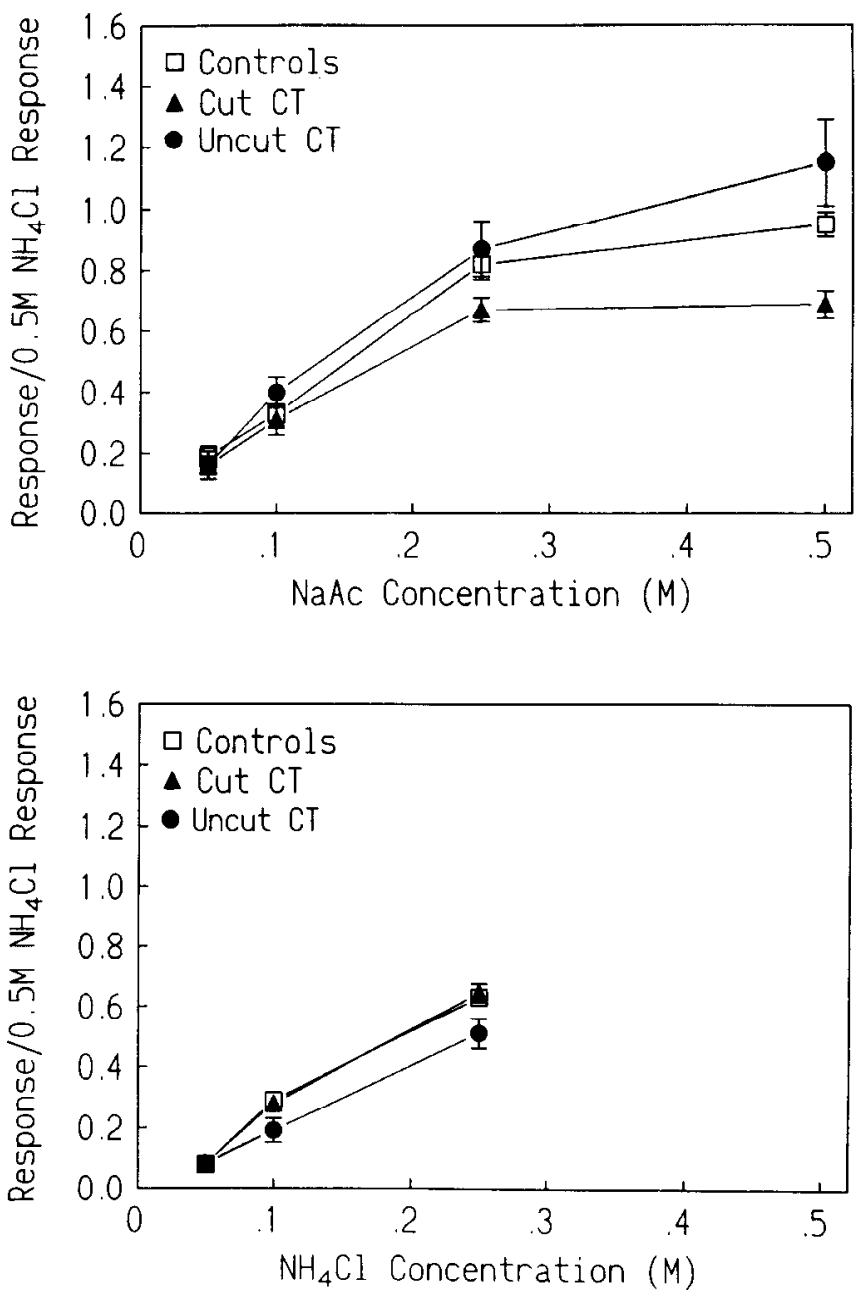

Figure 4. Mean $( \pm \mathrm{SEM})$ relative responses to a concentration series of $\mathrm{NaAc}$ (top) and $\mathrm{NH}_{4} \mathrm{Cl}$ (bottom) from the regenerated chorda tympani nerve in controls, sodium-restricted rats $(C u t C T)$, and the intact nerve in rats where the contralateral chorda tympani regenerated under sodium restriction (Uncut $C T$ ).

nificantly below control responses throughout the experiment (up to $120 \mathrm{~d}$ postsectioning).

\section{Responses from the uncut chorda tympani nerve contralateral} to the regenerated side

In contrast to the significantly lowered sodium responses from the regenerated chorda tympani in sodium-restricted rats, the intact nerve $(n=8)$ was unexpectedly supersensitive to $\mathrm{NaCl}$ at all concentrations above $0.05 \mathrm{M}(t=3.49-4.59 ; p=0.002-$ 0.0002 ; Figs. 2, 3). Mean responses from the uncut chorda tympani nerve in sodium-restricted rats were up to $40 \%$ greater than those in controls. While $\mathrm{NaCl}$ responses from the uncut chorda tympani nerve in sodium-restricted rats were consistently higher than $\mathrm{NaCl}$ responses in controls, responses to $\mathrm{NaAc}$ and $\mathrm{NH}_{4} \mathrm{Cl}$ were not significantly different $(p>0.10$; Fig. 4$)$. The supersensitivity to sodium salts is more prominent when response comparisons are made between the two sides of the tongue instead of between control and sodium-restricted rats. There was as much as a twofold difference in $\mathrm{NaCl}$ and $\mathrm{NaAc}$ responses between the regenerated and intact chorda tympani nerves in sodium-restricted rats. In contrast, responses to all stimuli were similar for both chorda tympani nerves in cut controls. 
$0.5 \mathrm{M} \mathrm{NaCl}$

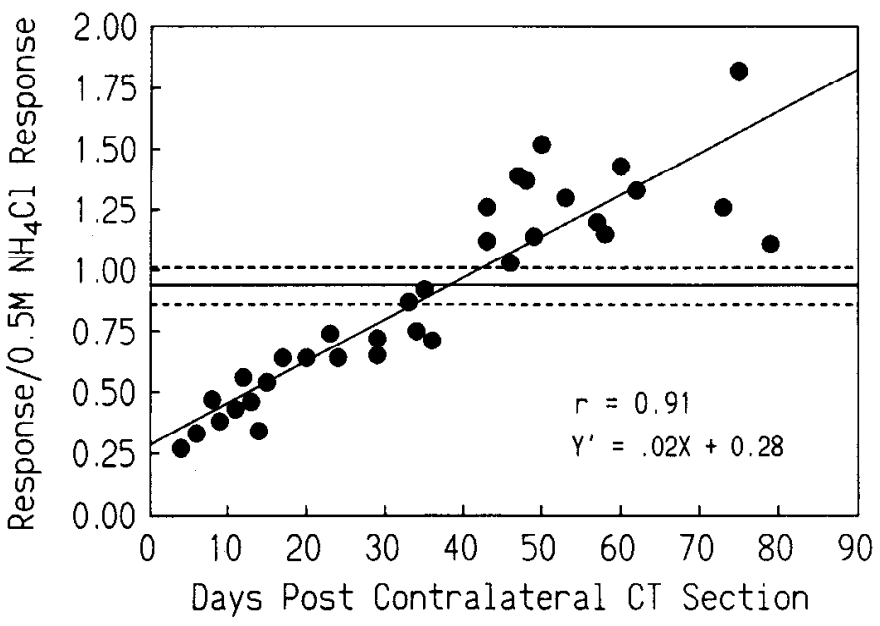

Figure 5. Relative responses to $0.5 \mathrm{M} \mathrm{NaCl}$ from the intact chorda tympani nerve in sodium-restricted rats shown as a function of days after the contralateral chorda tympani was sectioned. The line of best fit is shown through the data points representing each rat's response and defined by the linear correlation coefficient and regression equation noted in the lower right corner. Dashed lines represent $95 \%$ confidence intervals derived from control data (see Fig. 6).

\section{$\mathrm{NaCl}$ responses after lingual application of amiloride}

Although response differences existed between the intact and regenerated chorda tympani nerves in sodium-restricted rats, these differences were eliminated following amiloride (Fig. 3). For example, the mean suppression of $0.5 \mathrm{M} \mathrm{NaCl}$ responses was $33 \%$ in the regenerated nerve and $70 \%$ in the intact nerve. This differential suppression yields similar amiloride-insensitive responses from the two sides of the tongue (Fig. 3). Likewise, all differences in responses between sodium-restricted rats receiving a chorda tympani section and controls were eliminated by the sodium transport blocker (Fig. 3). Thus, functional alterations in the amiloride-sensitive sodium channel appear to account in large part for the response differences between sides of the tongue and between groups.

\section{Time-dependent changes in the uncut chorda tympani nerve after sectioning}

As shown above, the intact chorda tympani nerve in sodiumrestricted rats was supersensitive to sodium salts following regeneration of the contralateral nerve. In order to examine the time course of this supersensitivity, responses from intact chorda tympani nerves were recorded systematically at various time points following sectioning of the contralateral nerve.

Surprisingly, responses to $\mathrm{NaCl}$ and $\mathrm{NaAc}$ were unusually low within days following sectioning of the contralateral chorda tympani. Responses gradually, but predictably, increased to the supersensitive level during the next $40-50 \mathrm{~d}$ (Fig. 5). For example, the mean relative response ratio of $0.5 \mathrm{M} \mathrm{NaCl} / 0.5 \mathrm{M} \mathrm{NH}_{4} \mathrm{Cl} 4$ $\mathrm{d}$ after contralateral nerve cut was 0.27 and then gradually increased to approximately $1.1,45 \mathrm{~d}$ postsectioning (Fig. 5). The response recovery appeared to follow a linear function that explained as much as $83 \%$ of the variance. It should be noted that the recovery of responses to all concentrations of $\mathrm{NaCl}$ was similar to that shown in Figure 5. That is, the time-response functions for all four $\mathrm{NaCl}$ concentrations had high correlations $(p<0.0001)$ and similar slopes $(p>0.10)$.

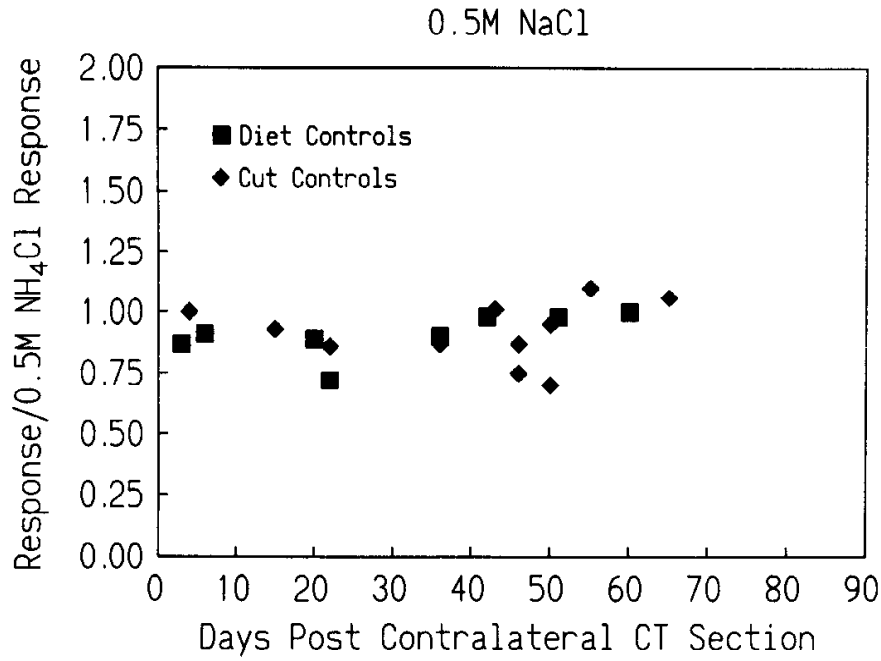

Figure 6. Relative responses to $0.5 \mathrm{M} \mathrm{NaCl}$ from the chorda tympani nerve in diet and cut controls shown as a function of days after placing rats on the sodium-restricted diet (Diet Controls) or after the contralateral chorda tympani was sectioned in sodium-replete rats ( $\mathrm{Cut} \mathrm{Con-}$ trols).

The changing responses with time following sectioning of the contralateral chorda tympani nerve were specific to rats that received the sectioning and were placed on the sodium-restricted diet. The intact nerves in cut and diet controls responded "normally" to all stimuli regardless of time after cut or after dietary manipulation, respectively (Fig. 6). Therefore, as noted earlier, altered chorda tympani sensitivity to $\mathrm{NaCl}$ and $\mathrm{NaAc}$ was seen only in rats that received a chorda tympani section plus the sodium-restricted diet.

\section{Recovery of intact nerve function without reinnervation by the sectioned nerve}

The dynamic changes in chorda tympani responses to sodium salts shown in Figure 5 may relate to degeneration and subsequent regeneration of the contralateral nerve and its associated taste receptor cells. That is, the gradual reinnervation of the chorda tympani may induce the time-dependent response increases in sodium sensitivity of the intact nerve. To assess this possibility, recordings from the intact nerve in sodium-restricted rats were accomplished as before in five additional rats, with the exception that the sectioncd nerve was not allowed to make functional connections. Accordingly, the chorda tympani nerve was sectioned every $14 \mathrm{~d}$ after the initial sectioning, for a total of five cuts, to prevent functional reinnervation. As seen in Figure 7, the function describing the increase in responses to $0.5 \mathrm{M} \mathrm{NaCl}$ following multiple sections was similar to that observed following a single cut. Similarities also occurred in response to lower $\mathrm{NaCl}$ concentrations and to $\mathrm{NaAc}$. Therefore, the graded increases in sodium responses after contralateral chorda tympani section in sodium-restricted rats is not due to the gradual reinnervation of the tongue by the originally sectioned nerve.

\section{Discussion}

The findings described here demonstrate that the adult peripheral gustatory system is highly "plastic" under certain conditions. Specifically, unilateral chorda tympani section in rats fed a sodium-restricted diet at adulthood results in a regenerated 
nerve that has attenuated responses to sodium salts. In the same rat, the contralateral, intact nerve is supersensitive to sodium salts. The supersensitivity does not occur immediately after sectioning the contralateral chorda tympani but occurs as responses increase systematically following an initially subnormal response. This occurs in the absence of reinnervation. Finally, the basis for all these changes relates to functional alterations in amiloride-sensitive sodium channels. Notably, these large effects occur only under certain conditions. Simply sectioning the chorda tympani nerve or simply placing adult rats on a sodiumrestricted diet does not alter responses significantly from what is typical in adult, normal rats. Instead, chorda tympani sectioning must be accompanicd by the low-sodium diet in order to produce response alterations.

The attenuated sodium response in the regenerated chorda tympani nerve of adult sodium-restricted rats parallels what we have observed in developmentally sodium-restricted rats (Hill, 1987; Hill and Przekop, 1988). Both manipulations result in a large attenuation in the relative $\mathrm{NaCl}$ response. The present findings are especially significant because, as noted here in the diet control rats, chorda tympani function could not be altered if the dietary manipulation occurred solely at adulthood. Therefore, sodium transduction can be significantly attenuated at adulthood (i.e., a $30 \%$ or greater decrease from normal responses) only when the sodium restriction is combined with loss of taste bud innervation. It is not clear whether the numbers and/or the conductance of the amiloride-sensitive channel is responsible for the change. However, such an attenuation of the sodium response apparently occurs throughout multiple generations of taste receptor cells. Turnover rates for adult rat taste receptor cells are about every $10 \mathrm{~d}$ (Beidler and Smallman, 1985). Therefore, it is likely that 4-12 generations of receptor cells were present between the time of sectioning and the time when recordings were conducted. It must be noted that others report changes in chorda tympani function in adult sodiumrestricted rats (Contreras and Frank, 1979); however, the magnitude of alteration is much smaller than reported here.

The alterations in chorda tympani responses of developmentally sodium-deprived rats are comparable to response changes in the regenerated nerve of adult sodium-deprived rats. This similarity indicates common regulatory mechanisms. Specifically, it may be that newly formed taste receptors (either during normal development or during regeneration) are susceptible to the array of physiological consequences induced by the sodiumrestricted diet. For example, changes in circulating hormones and growth factors induced by low dietary sodium may have long-term influences on progenitor cells as they produce taste receptor cells. A number of candidate hormones and growth factors exist that regulate the amiloride-sensitive sodium channel in other epithelia (e.g., Garty and Edelman, 1983; Garty and Benos, 1988; Blazer-Yost et al., 1989); however, little is known currently about the effects of dietary sodium restriction on such agents and the relevant time course of effects.

Perhaps the most unexpected and most intriguing findings demonstrated here are the dynamic changes that result in the intact chorda tympani nerve in operated rats receiving the lowsodium diet. Such changes indicate some form of communication between the cut side of the tongue and the contralateral, intact side. However, the pathway for communication between sides of the tongue is not clear. It is unlikely that significant sprouting from the intact chorda tympani nerve to the denervated side of the tongue occurs (Kinnman and Aldskogius, 1988),

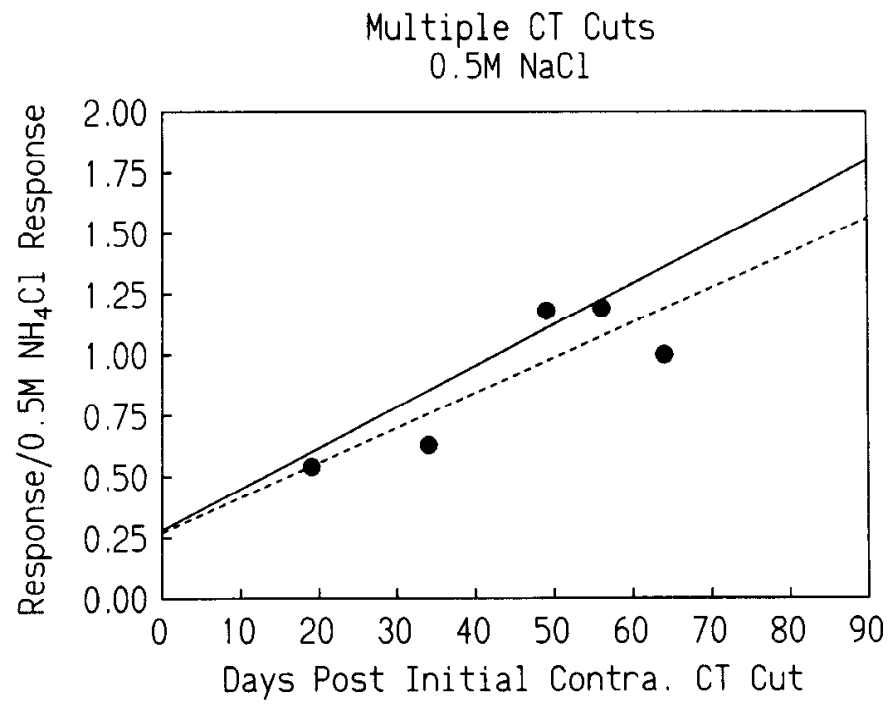

Figure 7. Relative responses to $0.5 \mathrm{M} \mathrm{NaCl}$ from the intact chorda tympani nerve in sodium-restricted rats shown as a function of days after the contralateral chorda tympani was initially sectioned. The sectioned chorda tympani was not allowed to reinnervate the tongue. The solid line is the line of best fit derived from data shown in Figure 5, and the dashed line describes the linear regression line for the five data points shown on the graph.

which could result in the effects shown here. However, potential circuits may exist centrally, whereby loss of function is communicated to the contralateral side via efferent control. Although there are physiological (Hellekant, 1971) and behavioral studies (e.g., Yanagisawa et al., 1992) suggesting a centrally mediated interaction between the two sides of the tongue, the neurobiological substrates for such interactions have not been demonstrated conclusively. Moreover, it is not clear that efferents modulate taste bud function directly (Hellekant and Hagstrom, 1974). In fact, morphological studies indicate that the efferent, chorda tympani projections to taste buds are virtually absent (Farbman and Hellekant, 1978). Finally, as seen in Figures 5 and 7 , changes in intact taste receptors are seen even when the contralateral nerve is prevented from reinnervating taste buds. Thus, the origin of potential efferent messages is not from a regenerating chorda tympani nerve.

Another possible mechanism for these results, which essentially has been overlooked, is that peripheral processes rather than central processes influence taste function. Local circulating factors liberated (or prevented from being liberated) following nerve cut may sequentially decrease then increase amiloridesensitive sodium channel function compared to that in controls; again, it is not clear whether such changes relate to modifications in the number of channels and/or their conductance properties. However, evidence for dynamic changes in membrane properties distant from nerve section has been presented by Simon et al. (1993). They showed that sodium flux in vitro across nongustatory lingual epithelia from adult, sodium-replete dogs and rats was attenuated within days following unilateral chorda tympani section. The lowered epithelial sodium transport was followed by a systematic return to control levels within about 40 d. In contrast, chorda tympani taste responses were unaffected on either side of the tongue. Importantly, this occurred on the intact side as well as the chorda tympani-sectioned side of the tongue, indicating as in the present study that significant phys- 
iological influences occur between denervated and intact lingual epithelia. Since we found an effect on neural taste responses, it is apparent that sodium deprivation introduces additional factors that are important in regulation of taste receptor cell function.

A possible substrate for peripheral interactions may be related to wound healing following denervation. Since sectioning the chorda tympani results in degeneration and subsequent regeneration of taste receptor cells and neural elements, it is possible that cellular processes invoked following tissue damage and subsequent wound healing also occur in the gustatory system. It is unclear at this time how these or other factors liberated (or suppressed) by the immune system can influence the function of distant taste receptor cells; however, it is clear that circulatory and immune networks exist to transport such factors in the tongue (Hellekant, 1976; Maher, 1985). As an aside, metabolic factors are important in suppressing immune function (Levenson and Demetriou, 1992), suggesting that dietary constituents, such as sodium, may play a role in the expression of immune system products.

Regardless of the specific mechanism, we have shown that the amiloride-sensitive sodium channel is extremely labile, even in the adult rat, and that regenerating taste receptors are susceptible to environmental influences. Further, we have demonstrated that profound interactions in taste function occur between the two halves of the tongue. It will be important to identify the cellular and/or neural pathways by which these dynamic interactions occur to understand regulation of gustatory function in intact animals and in animals sustaining ncural insult.

\section{References}

Beidler LM (1953) Properties of chemoreceptors of tongue of rat. J Neurophysiol 16:595-607.

Beidler LM, Smallman RL (1985) Renewal of cells within taste buds. J Cell Biol 27:263-272.

Beidler LM, Fishman IY, Hardiman CW (1955) Species differences in taste responses. Am J Physiol 181:235-239.

Blazer-Yost BL, Cox M, Furlanetto R (1989) Insulin and IGF I receptor-mediated $\mathrm{Na}^{+}$transport in toad urinary bladders. Am J Physiol 257:C612-C620.

Cheal M, Oakley B (1977) Regeneration of fungiform taste buds: temporal and spatial characteristics. J Comp Neurol 200:609-626.

Cheal M, Dickey WP, Jones LB, Oakley B (1977) Taste fiber responses during reinncrvation of fungiform papillac. J Comp Ncurol 172:627646.

Contreras RJ, Frank ME (1979) Sodium deprivation alters neural responses to gustatory stimuli. J Gen Physiol 73:569-594.

Erickson RP (1966) Nontraumatic headholders for mammals. Physiol Behav 1:97-98.

Farbman AI (1965) Fine structure of the taste bud. J Ultrastruct Res 12:328-350.

Farbman AI, Hellekant G (1978) Quantitative analyses of the fiber population in rat chorda tympani nerves and fungiform papillae. Am J Anat 153:509-522.
Garty H, Benos DJ (1988) Characteristics and regulatory mechanisms of the amiloride-blockable $\mathrm{Na}^{+}$channel. Physiol Rev 68:309-337.

Garty H, Edelman IS (1983) Amiloride-sensitive trypsinization of apical sodium channels: analysis of hormonal regulation of sodium transport in toad bladder. J Gen Physiol 81:785-803.

Guth L (1971) Degeneration and regeneration of taste buds. In: Handbook of sensory physiology, Vol IV, Chemical senses, Pt 2 (Beidler LM, ed), pp 63-74. New York: Springer.

Hård af Segerstad C, Hellekant G, Farbman AI (1989) Changes in number and morphology of fungiform taste buds in rat after transection of the chorda tympani or chorda-lingual nerve. Chem Senses 14: 335-348.

Harper HW, Knight BW (1987) The correct method of signal processing for whole-nerve recordings. Chem Senses 12:664.

Hellekant G (1971) Efferent impulses in the chorda tympani nerve of the rat. Acta Physiol Scand 83:203-209.

Hellekant G (1976) The blood circulation of the tongue. Front Oral Physiol 2:130-145.

Hellekant G, Hagstrom EC (1974) Efferent chorda tympani activity and salivary secretion. Acta Physiol Scand 90:533-543.

Hill DL (1987) Susceptibility of the developing rat gustatory system to the physiological effects of dietary sodium deprivation. J Physiol (Lond) 393:413-424.

Hill DL, Bour TC (1985) Addition of functional amiloride-sensitive components to the receptor membrane: a possible mechanism for altered taste responses during development. Dev Brain Res 20:310313.

Hill DL, Przekop PR (1988) Influences of dietary sodium on functional taste receptor development: a sensitive period. Science 241:18261828.

Hill DL, Mistretta CM, Bradley RM (1982) Developmental changes in taste response characteristics of rat single chorda tympani fibers. J Neurosci 2:782-790.

Kinnman E, Aldskogius J (1988) Collateral reinnervation of taste buds after chronic sensory denervation: a morphological study. J Comp Neurol 270:569-574.

Levenson SM, Demetriou AA (1992) Metabolic factors. In: Wound healing: biochemical and clinical aspects (Cohen IK, Dicgelmann RF, Lindblad WJ, eds), pp 248-273. Philadelphia: Saunders.

Maher WP (1985) Arterial, venous, lymphatic pathways in dorsal mucosa of dog tongue. Microcirc Endothelium Lymphatics 2:161184.

Mistretta CM (1972) Topographical and histological study of the developing rat tongue, palate and taste buds. In: Oral sensation and perception. The mouth of the infant (Bosma JF, ed), pp 163-187. Springfield, IL: Thomas.

Oakley B, Benjamin RM (1966) Neural mechanisms of taste. Physiol Rev 46:173-211.

Oakley B, Keppel E, Hughes S (1984) Trophic capacity of experimentally lengthened gustatory axons. Dev Brain Res 16:195-201.

Olmsted JMD (1921) Effects of cutting the lingual nerve of the dog. J Comp Neurol 33:149-154.

Simon SA, Elliott EJ, Erickson RP, Holland VF (1993) Ion transport across lingual epithelium is modulated by chorda tympani nerve fibers. Brain Res, in press.

Yanagisawa K, Bartoshuk LM, Karrer TA, Kveton JF, Catalanotto FA, Lehman CD, Weiffenbach JM (1992) Anesthesia of the chorda tympani nerve: insights into a source of dysgeusia. Chem Senses 17:724.

Zelena J (1964) Development, degeneration and regeneration of receptor organs.In: Progress in brain research, Vol 13, Mechanisms of neural regeneration (Singer M, Schadé JP, eds), pp 175-213. Amsterdam: Elsevier. 